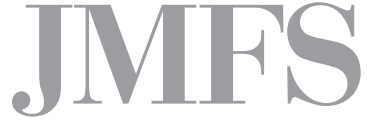

Journal of Management and Financial Sciences
Volume XII

Issue 37 (June 2019

pp. $47-59$

Warsaw School of Economics

Collegium of Management and Finance

Hanna Banaszek

Wydział Prawa i Administracji

Uniwersytet Gdański

\title{
Enforcement and sanctioning system deficit under UNCLOS? A closer look at the Fukushima accident
}

\begin{abstract}
The marine pollution is rarely debated from the perspective of land-based sources of pollution under the 1982 UN Convention on the Law of the Sea (UNCLOS). This article centres not only on a land-based source of pollution of the sea, but also a very particular one - the 2011 Fukushima Daiichi accident. Apart from causing severe infrastructural damage and posing a radiation-related threat to the public, Fukushima has had a lasting impact on the marine environment, too. Especially, since the operator of the plant has so far been unsuccessful in completely eliminating the radioactive leakage into the seas. This article considers the actual impact of the accident on the marine life along with the relevant recovery and remediation measures aimed to limit said impact, all in the light of the provisions of UNCLOS. Especially, with regard to its problematic (rather underdeveloped) enforcement and sanctioning system which should be more balanced, considering the various contemporary sources of pollution of the seas. Notwithstanding, UNCLOS will most likely further strengthen international cooperation with the ultimate aim of preventing the pollution of the world's oceans.
\end{abstract}

Keywords: United Nations, UNCLOS, international agreement, environmental law, international environmental law, energy, NPP

JEL Classification Codes: F53, K32, K33, Q40 


\section{Introduction}

Given the leakage of radioactive material coming into the sea from the crippled nuclear power plant in Fukushima, Japan, ever since the events of March $11^{\text {th }}, 2011$ - even based purely on one's intuitive judgment - it seems quite obvious that what we are dealing with is a case of pollution of the marine environment. In reality, however, whenever marine pollution is debated in terms of the applicable international law, more often than not it is the pollution coming from vessels, be it deliberate or accidental, in the form of oil, oil derivatives, chemicals, or even debris. This publication takes a different approach on the subject of pollution of the marine environment as it centres mainly on pollution coming from a very particular land-based source (the damaged nuclear power plant complex in Fukushima) in light of the applicable provisions of the 1982 United Nations Convention on the Law of the Sea (referred to as 'UNCLOS' or 'Convention').

In its second section, this article provides a more general view of the Fukushima accident, considering its general scale and impact, both regional, and to a certain extent, also global. The second section of the publication is, therefore, a brief account, descriptive in nature, of the events that ultimately led to the pollution of the marine environment and brought about the Fukushima accident's evolution from a 'local' problem to a global one. Making the accident exactly the sort of problem that requires that international law be observed - and more specifically, the 1982 United Nations Convention on the Law of the Sea.

The third section of this publication is meant as a summary of information regarding the actual pollution of seawater resulting from the Fukushima accident and its effects on the marine environment, as well as information regarding continual remediation and recovery measures aimed to mitigate said pollution. The results of studies and research described in said section help to wholly understand the extent of the damage dealt to the marine environment as a result of the accident and its impact over the years (up until 2018). Additionally, the considered results also provide a factual basis, enabling the Fukushima accident to be classified as a case of 'pollution from a land-based source' under UNCLOS.

The fourth section centres on the analysis of the applicable UNCLOS's regulations, with an additional focus on the problematic issue of its enforcement and sanctioning system, specifically with regard to the marine pollution from land-based sources. This paragraph includes a formal analysis of the relevant provisions under UNCLOS, allowing comparisons to be drawn between distinctive enforcement measures that apply to different sources of marine pollution.

The fifth and final section of the article provides a summary of the problematic regulations under UNCLOS, in light of the Fukushima accident and its impact, as described in previous sections of the article. This part also considers certain important conclusions already made with regard to the more commonly academically discussed sources of marine pollution (i.e. coming from vessels), as presented in publications regarding the enforcement of the international law 
by coastal and port states. Additionally, the final section of this article presents a brief view on possible future developments and international influence of the 1982 UN Convention on the Law of the Sea in this regard.

\section{The general scale and impact of the 2011 Fukushima accident}

At 2:46 pm on $11^{\text {th }}$ March 2011, an undersea magnitude 9.0 earthquake just off the coast of Japan caused a large tsunami which affected multiple on-shore structures, including also the Fukushima Daiichi nuclear power plant. Initially, as a result of the on-site system detecting seismic activities, all of the then-operational reactors did properly shut down and emergency diesel-powered generators activated in their stead. But about an hour later, when tsunami hit the plant, the emergency generators partially failed and there was a major accident sequence involving three of the reactors. This soon led to a series of explosions. The resulting radioactive pollution - as the contaminated water leaked into the surroundings of the plant, including ground waters and seawater - affected the marine and coastal environment [NOAA Earthquakes, 2018; WNA, 2018].

But in the immediate aftermath of the Fukushima accident in 2011 the focus was mainly on addressing the most direct and pressing threat, i.e. that of possible radioactive contamination affecting the human population in the area, especially due to the severity of the accident. Only then did it shift to remedying considerable infrastructural damage resulting from the underlying cause of the Fukushima accident; namely, a combination of disastrous weather phenomena: an earthquake and a powerful tsunami that soon followed.

Because of its magnitude, the so called 'Great East Japan Earthquake' alone did severe damage in the region, but the massive tsunami created by that earthquake did considerably more. According to the World Nuclear Association, as a result of the earthquake, "Japan moved a few metres east and the local coastline subsided half a metre" [WNA, 2018]. However, a 15-metre high tsunami proved even more damaging than the earthquake, especially in terms of direct loss of human life across the Japanese coastline [WNA, 2018].

The human death toll of the disaster in Fukushima alone was in fact considerable with as many as 2,202 dead [Harding, 2018; National Police Agency of Japan, 2018]. However, none of the fatalities in the area has so far been directly attributed to post-radiation cancer caused by the nuclear accident - apparently, there has not even been a single case of any cancer that could be directly linked to radiation coming from the crippled Fukushima facility [Harding, 2018], as people died mainly because of "evacuation stress, interruption to medical care and suicide" [Harding, 2018]. According to the National Police Agency of Japan, as of September 2018 , the general death toll in Japan resulting from the 2011 disaster is close to $16,000(15,896$ killed with 2,536 people missing) [National Police Agency of Japan, 2018], while other sources claim the figure is closer to 19,000 [WNA, 2018]. 
Irrespective of whether or not the chaotic mass-evacuation and the heavily compromised coastal infrastructure caused the number of casualties to increase, at the time of the accident the response of the Japanese authorities could hardly have been any different. It was obviously critical to first concentrate on measures aimed at saving and protecting human life, especially since the actual scale and range of radioactive contamination around Fukushima, including also that affecting the marine environment, was yet to be assessed.

Therefore, for a time, relatively little was said about the strictly environmental impact of the accident and more specifically, about the impact the Fukushima accident had had on the marine environment. When the immediate threat to human life and health was gone, the world's attention would rather shift to the problem of safety of nuclear power plants in general, and then, the future of nuclear power in Japan - both of which started resonating globally almost instantly. Most notably in Germany, which very soon after the Fukushima accident substantially modified its energy transformation programme in the form of so-called Energiewende and decided to completely turn away from nuclear power. Before the Fukushima accident, Germany's plan was to use nuclear as a 'bridging-technology' between high-emission carbon and low-emission but under-developed renewables.

Then, however, it turned out that TEPCO (i.e. Tokyo Electric Power Company Holdings, Incorporated - the operator of the Fukushima Daiichi nuclear power plant complex) was unable to stop radioactive contamination of the area in and around the damaged plant. And as the contaminated water continually leaked into the surroundings of the Fukushima nuclear power plant complex, it was clear that not only did it affect the coastal ground waters (on-shore), but also the marine environment (seawater). Then, what initially started as a national Japanese disaster became a potentially global environmental issue of a significantly larger scale. And naturally, the protection of the marine environment is a global problem, too, exactly as is the case with safety of nuclear installations, including power plants, and continual use of nuclear power around the world (as main, bridging or supporting power generation technology) from both economic and political perspectives.

The common qualities of all global problems are their scale and universality [Ciechanowicz-McLean, 2010, p. 101]. These two qualities are easily attributable to the protection of the marine environment, too, which - because of the sheer size of the world's oceans - should at all times go beyond any state borders. With oceans covering over 70 per cent of the Earth's surface and constituting the common heritage of mankind (per art. 136 UNCLOS), "for many people not only in the so-called Third World they are of enormous importance for food supplies, trade and economic growth. (...) Suffice it to say that the protection of the marine environment and the conservation of the ocean's living resources is in the interest of all States and their inhabitants, or to put it differently, in the interest of the international community of States" [König, 2002, p. 1].

The protection of the marine environment is, therefore, an issue whose importance is not to be questioned - due to the potential extent and range of any environmental threat [Ciechanowicz-McLean, 2010, p. 101], direct or indirect. This is precisely why we have 
international regulations governing the area of environmental protection including specifically the marine environment, most notably, the 1982 United Nations Convention on the Law of the Sea (UNCLOS). Article 192 UNCLOS (Part XII, 'Protection and preservation of the marine environment') provides for a general obligation of States to protect and preserve the marine environment - as the "States have the obligation to protect and preserve the marine environment".

But apart from UNCLOS, there are also other international agreements in this regard. Such globally applicable acts include: the International Convention on Civil Liability for Oil Pollution Damage (Brussels, 29 November 1969) and Protocol to the International Convention on Civil Liability for Oil Pollution Damage of 29 November 1969 (London, 19 November 1976), International Convention on the establishment of an international fund for compensation for oil pollution damage (Brussels, 18 December 1971), Convention on the prevention of marine pollution by dumping of wastes and other matter (signed in London, Mexico City, Moscow and Washington on 29 December 1972), International Convention for the Prevention of Pollution from Ships (MARPOL) (London, 2 November 1973) and its 1978 and 1997 Protocols (absorbing - 1978 Protocol - and significantly amending - 1997 Protocol - the original text of the parent convention of 1973).

Nevertheless, the specific aim of this particular publication is to present the relevant UNCLOS provisions regulating particularly the pollution of the marine environment from land-based sources, also with regard to their specific enforcement (and sanctioning) systems. And the Fukushima accident described in this section provides a factual background for such a legal analysis (see: part 3 of the article).

\section{The facts of the case: the Fukushima accident's impact on the marine environment and the remediation and recovery measures}

It has been almost eight years since the events in Fukushima, but even after all this time, caesium-contaminated radioactive water from the damaged nuclear facility is still flowing into the Pacific Ocean. It has to be emphasised, however, that over the years there has been a steady drop in the levels of radioactive pollution of the sea in direct vicinity of the damaged complex. Between 2013 and March 2018, the amount of leaking caesium-137 (the common radioactive isotope of caesium which is a product of fission) decreased from approximately 30 billion becquerels to 2 billion becquerels a day [The Japan Times, 2018]. And in accordance with the recent studies, the concentration of radiation per one litre of seawater, which amounts to 0.02 becquerel (water samples were collected off the coast several kilometres south of the Fukushima plant No. 1) is now "at a level that does not affect the local fishing industry" [The Japan Times, 2018]. This clearly means that the living organisms inhabiting the sampled areas of the ocean have not been seriously affected by the radioactive contamination. 
With regard to specifically that, i.e. the impact of the Fukushima accident on the marine life, it should be stated that according to some studies, "the radioactivity levels in the marine biota (...) were lower than predicted" [ScienceDaily, 2016] earlier (i.e. in the immediate aftermath of the accident). Also, the measured "exposures were too low for acute effects at the population level to be observed in marine organisms" [ScienceDaily, 2016].

However, according to the same reports, the variability in fish species making up the regional marine biota results in what has been referred to as 'numerous confounding factors' [ScienceDaily, 2016]. Different species have different positions in the food chain, they dwell in different places (water columns) and have different migratory patterns. Another contributing factor may also be that sediments slowed "the dispersal of the radioactive substances - since bottom-dwelling fish (benthic fish) are more exposed to contaminated sediments and receive higher dose rates than fish living in the higher levels of the water column" [ScienceDaily, 2016]. So, irrespective of the above-mentioned mostly optimistic findings, it has to be nonetheless emphasised that at least as of 2016 it was still too early to make conclusions with regard to long-term effects of the radioactive contamination of seawater as a result of the Fukushima accident [ScienceDaily, 2016].

It is very important to remember, however, that this radioactive contamination of seawater and its further-reaching effects (as discussed above) did not result from the Fukushima accident alone (i.e. from atmospheric deposits in the initial stages directly following the accident) [IRSN, 2016]. The actual mass-discharge (or discharges) of radioactive substances directly into the ocean was a result of using seawater, and to an extent, also fresh water [IRSN, 2016] to cool the damaged reactors after the accident [The Japan Times, 2018]. In the process, the contaminated coolant water leaked into the surroundings of the plant, including the ocean. So at least some of the resulting pollution of seawater in the area occurred due to a post-accident deliberate human-made decision, even if said decision is deemed valid and justified given the circumstances of the entire accident sequence and its further effects.

Coming back to the issue of the ongoing contamination of the Pacific Ocean (irrespective of its actual influence on the marine life, as discussed above), it should be emphasised that TEPCO (the operator of the Fukushima nuclear power plant) has so far failed to completely eliminate the problem of constant leakage of radioactive water from the Fukushima nuclear power plant complex. According to quite recent information presented by Japanese scientists, it is to be assumed that there is still some path through which the radioactive water flows from the complex and into the ocean [The Japan Times, 2018], irrespective of TEPCO's multiple efforts at stopping the leakage. These efforts included the construction of an 'underground ice wall', which was supposed to prevent the caesium-filled water accumulating in the lower sections of the buildings from leaking out of the structures and into the ground and the sea. Also, TEPCO built "a seawall aimed at preventing contaminated water from entering the ocean" [The Japan Times, 2018]. Although successful in terms of limiting the volume of said leakage and therefore, also the pollution, none of these measures have so far proven enough with regard to eliminating it altogether. 
Nonetheless, this problem has also led to at least some positives, for example, in terms of conceptual preparation for post-accident recovery regarding nuclear power plants. And more specifically, also with regard to the problem of leakage of contaminated water into the environment, so readily obvious in the Fukushima case. In this regard, certain member states of the OECD's Nuclear Energy Agency (NEA) have since started working towards resolving the problem of managing large amounts of contaminated water on-site through different water-storage ideas and long-term treatment of contaminated water [NEA \&OECD, 2016, p. 27].

Generally speaking, with regard to post-accident recovery, it should be noted, however, that both the Japanese operator of the plant (TEPCO) and the governmental authorities were fast to react, very efficient and mostly also effective in their combined efforts aimed at remedying the consequences of the Fukushima accident. Still, however, there remains a question of what the international community actually could do under the international law of the sea, if Japan had not reacted the way it had, or if the pollution of the ocean had been considerably more serious than it now seems to be - according to studies, at least (see above). It is not entirely clear if, under UNCLOS, the 'international community of States' even has a particular tool that would allow it to act accordingly and motivate Japan to take any particular measures had Japan failed to conform to the relevant standards and regulations regarding specifically the protection of the marine environment.

\section{The protection of the marine environment under UNCLOS}

Pollution of seawater (and therefore, also the marine environment) may be classified in a variety of ways, but from a legal perspective, the following division seems the most significant:

- based on the source of pollution: coming from land, vessels and other facilities designed to float or navigate on water, or from exploitation of the seabed, or even from the atmosphere;

- based on the type of pollutants: oil and oil-derivative pollution, other substances and materials;

- based on the intent of the polluting entity: deliberate acts of pollution (releases and discharges of substances into seawater, like dumping - and under Art. 1 sec. 1(5) UNCLOS, 'dumping' means “(i) any deliberate disposal of wastes or other matter from vessels, aircraft, platforms or other man-made structures at sea; (ii) any deliberate disposal of vessels, aircraft, platforms or other man-made structures at sea") and accidental, unintended pollution (e.g. as a result of failures, accidents, emergencies, etc.) [Ciechanowicz-McLean, 2010, p. 102]. The definition of 'pollution of the marine environment' under UNCLOS is actually very wide in scope. In accordance with Art. 1 sec. 4 of said act, 'pollution of the marine environment' means the introduction by man, directly or indirectly, of substances or energy into the marine environment, including estuaries, which results or is likely to result in such deleterious effects as harm to living resources and marine life, hazards to human health, hindrance to marine 
activities, including fishing and other legitimate uses of the sea, impairment of quality for use of sea water and reduction of amenities. So, there can be no doubt as to whether the Fukushima accident (or to be more specific, its effects and even certain post-accident measures taken by the operator of the plant) qualifies as 'pollution of the marine environment' under Art. 1 sec. 4 UNCLOS; it obviously does.

The issue of pollution of the marine environment from - specifically - land-based sources is regulated in the provisions of Article 207 UNCLOS. Under Art. 207 sec. 1 of said Convention, States are required to adopt such laws and regulations that "prevent, reduce and control pollution of the marine environment from land-based sources" (under art $207 \mathrm{sec} .1$ in fine UNCLOS, this also includes rivers, estuaries, pipelines and outfall structures, while considering internationally agreed rules, standards and recommended practices and procedures). Additionally, States are also required to take other measures that may be necessary to prevent, reduce and control such pollution (Art. $207 \mathrm{sec} .2$ UNCLOS) and shall also "aim to harmonize their policies (...) at the appropriate regional level" (art. $207 \mathrm{sec} .3$ UNCLOS). This obviously proves that the Convention is largely based on the idea of tightening and strengthening international cooperation of the states with the ultimate aim of preventing the pollution of the world's oceans, but the particulars, at least in terms of the shape of laws or policies that realize the aim of the convention, are decided by the state (or a group of states) alone.

Further to this effect, in accordance with Art. 207 sec. 4 UNCLOS, "States (...) shall endeavour (...) to establish global and regional rules, standards and recommended practices and procedures to prevent, reduce and control pollution of the marine environment from land-based sources" while considering "characteristic regional features, the economic capacity of developing States and their need for economic development". The same provision also requires the States to re-examine any such rules, standards and recommended practices and procedures if need be. Finally, under Art. $207 \mathrm{sec} .5$ of the Convention, any such "laws, regulations, measures, rules, standards and recommended practices and procedures (...) shall include those designed to minimize, to the fullest extent possible, the release of toxic, harmful or noxious substances, especially those which are persistent, into the marine environment".

The actual provision regarding the enforcement of Art. 207 UNCLOS in its entirety, i.e. enforcement with respect to pollution from land-based sources, is regulated in Art. 213 UNCLOS. In accordance with said provision, "States shall enforce their laws and regulations adopted in accordance with article 207" of the Convention and "adopt laws and regulations and take other measures necessary to implement applicable international rules and standards established through competent international organizations or diplomatic conference to prevent, reduce and control pollution of the marine environment from land-based sources". All of the above is certainly very important in terms of alignment of the respective national laws of states with the international rules. Particularly, in terms of their mutual purpose of symmetrical and properly balanced international cooperation towards the protection of the seas. But this provision falls short in terms of actually 'enforcing' the desired or required outcome on any entity that outright violates or otherwise fails to conform to Art. 207 UNCLOS. 
It could be argued that it is not within the originally intended and designed scope of the convention to actually deal with particular terms of enforcement in an international setting (this is decided on a national level), but this is not really the case, given the text of other enforcement-related provisions under UNCLOS. In contrast to Art. 213 discussed in the preceding paragraph, Articles 217, 218 and 220 of the same Convention are far more specific in defining the exact enforcement measures that may or shall be taken to realize the goals of UNCLOS with regard to protecting the marine environment.

However, it should be noted that the division of enforcement provisions is not entirely symmetrical to the traditionally accepted division of sources of marine pollution (partially incorporated into the Convention itself). To put it briefly, UNCLOS provides for enforcement with regard to different sources of pollution (e.g. from land, air, seabed activities) and additionally (separately), also for each category of states (flag - port - and coastal States), although, the latter may also be viewed in terms of being related to another particular source of pollution, i.e. that coming from vessels. But then, these regulations only concern pollution coming specifically from vessels and are designed to be applied by so-called 'flag States', 'port States', or 'coastal States', respectively.

For example, under Art. 217 of UNCLOS (regulating the enforcement of the convention by flag States), flag States shall, inter alia, ensure compliance by vessels which fly their flag or of their registry with applicable international rules and standards (sec. 1), "take appropriate measures in order to ensure that vessels" which fly their flag (or of their registry) "are prohibited from sailing, until they can proceed to sea in compliance" with relevant requirements (sec. 2), "ensure that vessels flying their flag or of their registry carry on board (the required) certificates" (sec. 3), but most importantly - under sec. 4 of Art. 207 UNCLOS, "if a vessel commits a violation of (the established) rules standards (...), the flag State (...) shall provide for immediate investigation and where appropriate institute proceedings in respect of the alleged violation irrespective of where the violation occurred or where the pollution caused by such violation has occurred or has been spotted". Additionally, under Art. 207 sec. 5-8 UNCLOS, flag States which conduct an investigation of the violation may also request the assistance of any other State, shall investigate violations alleged to have been committed by vessels flying their flag (and in the case where sufficient evidence is available to enable proceedings to be brought in respect of the alleged violation, flag States shall without delay institute such proceedings in accordance with their laws), shall inform the requesting state as well as competent international organization (s) of the action taken and its outcome (any such information to be made available to all States), and finally, penalties provided for by the laws and regulations of States for vessels flying their flag shall be adequate in severity to discourage violations wherever they occur.

Furthermore, in accordance with Art. 218 sec. 1 UNCLOS (regulating enforcement by port States), "when a vessel is voluntarily within a port or at an off-shore terminal of a State, that State may undertake investigations and, where the evidence so warrants, institute proceedings in respect of any discharge from that vessel outside the internal waters, territorial 
sea or exclusive economic zone of that State in violation of applicable international rules and standards" (as are established through the competent international organization or general diplomatic conference).

And with regard to coastal States, in accordance with Art. 220 sec. 2 UNCLOS, in a situation "where there are clear grounds for believing that a vessel navigating in the territorial sea of a State has, during its passage therein, violated laws and regulations of that State adopted in accordance with this Convention (UNCLOS) or applicable international rules and standards for the prevention, reduction and control of pollution from vessels, that State (...) may undertake physical inspection of the vessel relating to the violation and may (...) institute proceedings, including detention of the vessel". Additional complementary regulations allowing for other particular enforcement measures to be taken under the applicable laws by the interested state (or states) are also introduced by other sections of the same Article of the Convention (see also: Art. 220 sec. 3-6 UNCLOS).

Therefore, there can be no real doubt as to whether there is a possibility to actually include more specific enforcement-related provisions in the international law of the sea [König, 2002, pp. 4-6]. It has already happened, but only with regard to a very particular and limited scope - at least as of today.

\section{Summary}

The problem with UNCLOS's regulations regarding the environmental protection of the oceans lies in the fact that while the Convention is quite specific and symmetrical in describing and categorising the different sources of marine pollution (which is a good quality), its respective enforcement regulations are not equally balanced. This is understandable - given the problematic history behind the creation of UNCLOS, and the States' reluctance to agree on specific crucial parts of the Convention [Carpenter, 2011, pp. 55-57; UN, 1998]. So, it is hard to imagine a creation of a standardized wider enforcement and/or sanctioning system. That would probably lead to a major discussion involving the entire 'community of States' at the UN level.

However, as can be seen from the Fukushima accident, there are certain rare cases (sources) of marine pollution that may be (at least potentially) even more damaging to the environment than most commonly occurring marine pollution - i.e. that coming from vessels - but also than any other source considered in the Convention. Still, there are no provisions that would provide specific grounds for more direct actions, in stark contrast to the regulations related to pollution originating from vessels and the respective measures that may or shall be taken by flag, port or coastal States under UNCLOS (with regard to particular zones of the seas).

The issue of enforcement and virtual lack of international sanctions under UNCLOS is by no means new, at least not in terms of academic interest and debate. With regard to specifically the enforcement of the international law of the sea by coastal and port states, Professor D. König 
has pointed out that as far as international environmental law is concerned, "a structural enforcement deficit cannot be denied" [König, 2002, p. 2], effectively meaning that despite the applicable international regulations, the states operate in a more or less "decentralised system" [König, 2002, p. 2]. Specifically, as there is no particular authority responsible for enforcing the regulations of the international law in this respect (the closest to such a centralised body is the International Seabed Authority - its authority, however, covers the protection of deep sea-bed, while the enforcement of the international law of the sea is basically up to particular states) [König, 2002, p. 2]. However, as can be seen from the preceding section of this publication, this kind of enforcement, too, is rather limited in scope given the actual variety of sources of pollution threatening the world's oceans.

With regard to the above cited provisions of UNCLOS forming the structures of its enforcement model, D. König has also observed, however, that even if port States mostly "have the right to enforce their" respective laws "against foreign vessels, which are voluntarily within their ports, when an illegal discharge has occurred in their own internal waters, territorial sea or EEZ” (i.e. exclusive economic zone), [König, 2002, pp. 4-6], they are still entitled to act for the benefit of international common interests of all states (with regard to other States' zones and even the high seas) "against a foreign vessel in case of any illegal operational discharge" [König, 2002, pp. 4-6, 14] under Art. 218 sec. 1 UNCLOS. It proves that, at least to a certain extent, UNCLOS already provides for State action that indirectly benefits other entities (States) as well and does not just serve the interests of a particular State taking action in a given case [König, 2002, p. 14].

It should be, therefore, strongly emphasised that irrespective of the future format of international provisions governing the area of enforcement (and maybe even the sanctioning system) with regard to other sources of marine pollution, too, the common international interest should never be secondary to the state's own interest in enforcing a particular regulation and taking action on behalf of the community of states. And as A. Carpenter put it, "although UNCLOS has now been in force for over 15 years, it is important to note that with increasing awareness of global issues such as climate change, and increasing scientific knowledge of the impacts of different chemicals entering the marine environment (...), the Convention and the United Nations will play a continuing role in ensuring that state responses to those issues" [Carpenter, 2011, p. 59]. This is just as true almost a decade later.

\section{References:}

\section{Legal documents}

1. UNCLOS, United Nations Convention on the Law of the Sea of 10 December 1982, signed in Montego Bay. Consolidated version retrieved from: http://www.un.org/depts/los/convention_agreements/convention_overview_convention.htm [accessed: 1 March 2019]. 


\section{Publications}

1. Carpenter, A. (2011). International Protection of the Marine Environment. [In:] The Marine Environment. A.D. Nemeth (Ed), pp. 51-86.

2. Ciechanowicz-McLean, J. (2010). Ochrona zasobów przyrodniczych morza. [In:] Wybrane problemy prawa ochrony środowiska. M. Pchałek, B. Rakoczy (Eds), pp. 101-125.

3. IRSN (2016). Situation of the contamination of the marine environment in 2015, following the Fukushima Daiichi nuclear power plant accident. Institut de Radioprotection et de Sûréte Nucléaire, March 2016. Retrieved from: https://www.irsn.fr/EN/publications/thematic-safety/ fukushima/fukushima-2016/Documents/22-IRSN_Fukushima-2016_Environment-Marine-Contamination_201603.pdf [accessed: 7 Jan 2019].

4. König, D. (2002). The Enforcement of the International Law of the Sea by Coastal and Port States. Heidelberg Journal of International Law, Vol. 62, International Law Enforcement and Dispute Settlement - Recent Developments and the Law of the Sea, International Symposium organized on the occasion of the sixtieth birthday of Rüdiger Wolfrum at the Max Planck Institute for Comparative Public Law and International Law, Heidelberg, 14 and 15 December 2001, pp. 1-16.

5. NEA \& OECD (2016). Nuclear Energy Agency and Organisation for Economic Cooperation and Development. Five Years after the Fukushima Daiichi Accident: Nuclear Safety Improvements and Lessons Learnt. NEA No. 7284.

6. UN (1998). The United Nations Convention on the Law of the Sea (A historical perspective). Originally prepared for the International Year of the Ocean 1998, United Nations, Oceans and Law of the Sea: Division for Ocean Affairs and the Law of the Sea. Retrieved from: http:// www.un.org/Depts/los/convention [accessed: 11 Jan 2019].

\section{Press and occasional articles}

1. Harding, R. (2018). Fukushima nuclear disaster: did the evacuation raise the death toll? The Financial Times, 11 March 2018. Retrieved from: https://www.ft.com/content/000f864e-22ba-11e8-add1-0e8958b189ea [accessed: 15 Nov 2018].

2. ScienceDaily (2016). Impact of the Fukushima accident on marine life, five years later ScienceDaily, 18 October 2016. Retrieved from: www.sciencedaily.com/releases/2016/10/161018141309. htm [accessed: 7 Jan 2019].

3. The Japan Times (2018). Seven years on, radioactive water at Fukushima plant still flowing into ocean, study finds. The Japan Times, 29 March 2018. Retrieved from: https://www.japantimes. co.jp/news/2018/03/29/national/seven-years-radioactive-water-fukushima-plant-still-flowingocean-study-finds/\#.XAFY5PZFzsZ [accessed: 19 Sept 2018].

\section{Internet materials}

1. National Police Agency of Japan (2018). Police Countermeasures and Damage Situation associated with 2011 Tohoku district - off the Pacific Ocean Earthquake September 10, 2018. Emergency Disaster Countermeasures Headquarters, National Police Agency of Japan. Retrieved from: https://www.npa.go.jp/news/other/earthquake2011/pdf/higaijokyo_e.pdf [accessed: 29 Nov 2018]. 
2. NOAA (2018). Earthquakes and Nuclear Power Plants. U.S. Department of Commerce, National Oceanic and Atmospheric Administration. Retrieved from: http://sos.noaa.gov/Datasets/ dataset.php?id=469 [accessed: 18 Nov 2018].

3. WNA (Updated: October 2018). Fukushima Daiichi Accident. World Nuclear Association. Retrieved from: http://www.world-nuclear.org/information-library/safety-and-security/ safety-of-plants/fukushima-accident.aspx [accessed: 20 Nov 2018]. 